INTERIM REPORT

\title{
ADVANCES IN MODELING OF \\ CHEMICAL VAPOR INFILTRATION \\ FOR TUBE FABRICATION
}

Thomas L. Starr

April 1998

Report prepared by

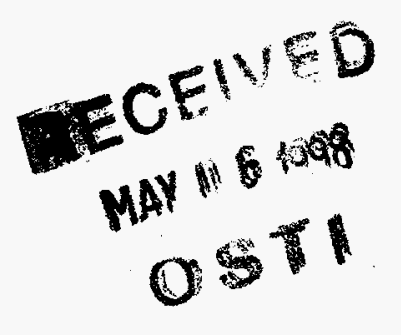

School of Materials Science and Technology

Georgia Institute of Technology

Atlanta, Georgia 30332

under

Subcontract 19X-55901

for

Oak Ridge National Laboratory

Oak Ridge, Tennessee 37831

managed by

Lockheed Martin Energy Systems

for the

U.S. Department of Energy

under Contract No. DE-AC05-84R21400

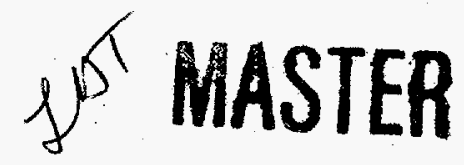




\section{DISCLAIMER}

This report was prepared as an account of work sponsored by an agency of the United States Government. Neither the United States Governmeat nor any agency thereof, nor any of their employees, makes any warranty, express or implied. or assumes any legal liability or responsibility for the accuracy, completeness, or usefulpess of any information, apparatus, product, of process disclosed, of represents that its use would not infringe privately owned rights. Reference berein to any specific commercial produce, process, or service by trade name, trademart, manufacturer, or otherwise does not necessarily constitute or imply its endorsement, recommendacion, or favoring by the United States Government or any ageacy thereof. The views and opinions of authors expressed herein do not necessarily state or reflect those of the United States Governmeat or any agency thereof. 


\section{DISCLAIMER}

Portions of this document may be illegible in electronic image products. Images are produced from the best available original document. 


\title{
ADVANCES IN MODELING OF CHEMICAL VAPOR INFILTRATION \\ FOR TUBE FABRICATION
}

\author{
Thomas L. Starr
}

April 1998

Research sponsored by the U.S. Department of Energy,

Fossil Energy

Advanced Research and Technology Development Materials Program

Report prepared by

School of Materials Science and Engineering

Georgia Institute of Technology

Atlanta, Georgia 30332

under

Subcontract 19X-55901

for

Oak Ridge National Laboratory

Oak Ridge, Tennessee 37831

managed by

Lockheed Martin Energy Systems

for the

U.S. Department of Energy

under Contract No. DE-AC05-84R21400 
INTRODUCTION

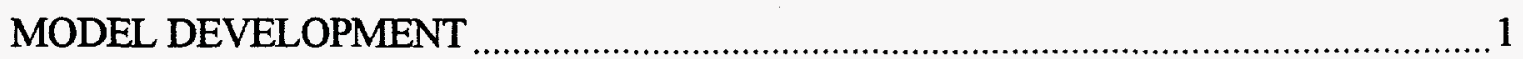

Improved Numerical Method for Radiative Heat Transfer ........................................ 1

Adaptation to Windows Operating System ...........................................................

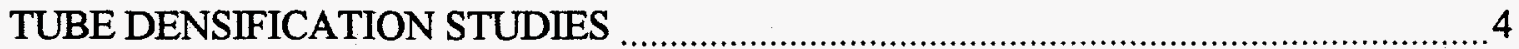

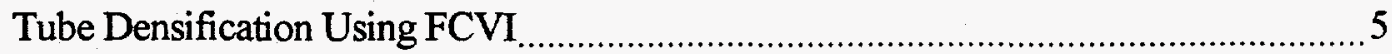

Hybrid Process For Gas-Tight Tubes ....................................................................... 10

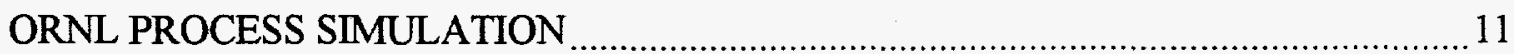

SUMMARY

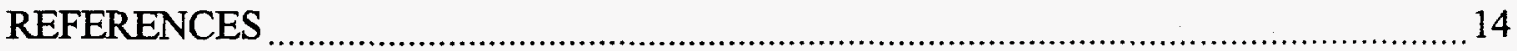




\section{INTRODUCTION}

The forced flow/thermal gradient chemical vapor infiltration process (FCVI) can be used for fabrication of tube-shaped components of ceramic matrix composites. Recent experimental work at Oak Ridge National Laboratory (ORNL) includes process and materials development studies using a small tube reactor. Use of FCVI for this geometry involves significant changes in fixturing as compared to disk-shaped preforms previously fabricated. We have used our computer model of the CVI process to simulate tube densification and to identify process modifications that will decrease processing time. This report presents recent model developments and applications.

\section{MODEL DEVELOPMENT}

A "finite volume" method for modeling of FCVI has been described previously". It involves dividing the CVI system into an orthogonal array of volume elements. A value for each process parameter (temperature, pressure or reactant concentration) is specified at the grid point located at the center of each volume element. This array of discrete values approximates the real, continuous variation of the temperature, of the pressure and gas flow, and of the reagent concentration and reaction rate over the region of interest. A series of steady-state solutions to this model produces a simulation of the densification process.

Improved Numerical Method for Radiative Heat Transfer

For the ORNL infiltration system the temperature gradient through the tube preform is established by radiative heat gain from the hot reactor wall to the outside of the preform and radiative heat loss from the inside of the preform to the water cooled metal

\footnotetext{
Research sponsored by the U.S. Department of Energy, Fossil Energy Advanced Research and Technology Development Materials Program, DOE/FE AA 151010 0, Work Breakdown Structure Element GT-1(A)
} 
line running through the center of the reactor. Early versions of the CVI model included only conductive and convective heat transfer. This was suitable for disk infiltration where radiative effects are minor. Subsequently the model was modified to include radiative heat transfer using ray tracing between solid surfaces and including the net energy gain or loss as a source term in the finite volume equations ${ }^{2}$. This method yielded a good match between experimental and model temperature distributions for a tube infiltration system. Inclusion of radiation as a source term, however, can produce instability or slow convergence in the numerical algorithm used in the finite volume model. A recent modification to the model for heat transfer includes a "linearized" source term and yields more rapid and stable numerical convergence.

For a collection of interacting "gray" surfaces the heat transfer rate through the ith surface is given by the equation,

$$
\frac{Q_{i}}{A_{i}}=\varepsilon_{i}\left(\sigma T_{i}^{4}-\sum_{j=1}^{N} B_{j} F_{i j}\right)
$$

where $T_{i}$ is the surface temperature, $\varepsilon_{i}$ is the emissivity, $B_{i}$ is the radiosity, $Q_{i}$ is the radiative heat flow through surface $A_{i}, \sigma$ is the Stefan-Boltzmann constant and $F_{i j}$ is the "view factor" for a pair of surfaces. The radiosity $B_{i}$ of a surface is the sum of the emitted and reflected radiant flux,

$$
B_{i}=\varepsilon_{i} \sigma T_{i}^{4}+\left(1-\varepsilon_{i}\right) \sum_{j=1}^{N} B_{j} F_{i j}
$$

where $1-\varepsilon_{i}$ is the reflectance of surface $i$. Notice that the heat transfer for surface $i$ depends upon the radiosity of all of the radiating surfaces - the sum over all $j$. Therefore, the heat flow for all of the surfaces must be solved simultaneously. Given view factors $\left(F_{i j}\right)$ calculated by ray tracing, the emissivities of the surfaces and assuming the nodal temperatures are a good approximation for the surface temperatures, the radiosity at all faces within the simulation domain can be calculated and used to calculate the heat flux 
through each surface.

In the finite volume method ${ }^{3}$ node temperatures are calculate from a matrix equation in the form,

$$
A \vec{T}=\vec{b}
$$

where $\mathbf{A}$ is the tridiagonal matrix of interaction coefficients representing the conductive and convective heat exchange between a volume element and its neighbors, the vector $\mathbf{T}$ represents the node temperatures and the vector $\mathbf{b}$ includes the source terms. Since the interaction coefficients and source terms are, in general, temperature dependent this equation is solved iteratively starting from an initial "guess" of the temperate profile.

The most straightforward method for including the thermal radiation involves summing all of the heat transfers multiplied by the surface area of the exposed faces for the control volume. This sum gives the total amount of radiant energy which enters or leaves that volume and is included as a source term in the above matrix equation. However, for large temperature gradients the inclusion of the radiant source terms may produce divergence in the iterative solution scheme. While this numerical instability can be reduced by "damping" the source terms this also slows convergence, adding extra computation time to model runs. The fundamental cause of the instability is that the radiative source term is calculated using temperatures from the previous iteration cycle. Temperature adjustments in the current cycle have no effect until the next cycle leading to overshoot and oscillations about the correct temperature profile. Further, since the radiative contribution to the energy balance depends on the fourth power of temperature, small deviations from the "correct" temperature values can have a disproportionately large effect on the energy balance.

An improved method recognizes that part of the radiative energy exchange can be related to the current temperature of the node. This is seen by rearranging equation (1), 


$$
\begin{aligned}
\frac{Q_{i}}{A_{i}} & \approx \varepsilon_{i} \sigma\left(T_{i}^{*}\right)^{3} T_{i}-\varepsilon_{i} \sum_{j=1}^{N} B_{j} F_{i j} \\
& =S_{p} T_{i}+S_{c}
\end{aligned}
$$

where $T_{i}^{*}$ is the node temperature from the previous cycle. In this form the constant part of the source term $S_{c}$ remains on the right-hand-side of equation (2) but the linear part $S_{p}$ is included in the interaction coefficient matrix $\mathbf{A}$. The effect of this linearization of the radiative source term is more rapid and stable convergence of the model.

\section{Adaptation to Windows Operating System}

Originally developed for batch operation under the Unix operating system, the GTCVI code has been modified for use under Windows $95^{\mathrm{TM}}$. Changes include modification of file input and output formats and creation of a run control file which allows multiple, sequential model runs in background mode. Formatting requirements for material and reactant gas property files are simplified. Model code was delivered to ORNL along with test input files. Model operations and results at Georgia Tech and ORNL are identical.

\section{TUBE DENSIFICATION STUDIES}

An accurate CVI model can be used to investigate the potential for fabrication of gas-tight tubes for use as heat exchangers for fossil energy applications. Application of the CVI model to simulation of FCVI of tube shapes is demonstrated with an idealized tube infiltration geometry. The standard process necessarily yields tubes with residual gas permeability. A hybrid infiltration process can produce gas-tight tubes. 


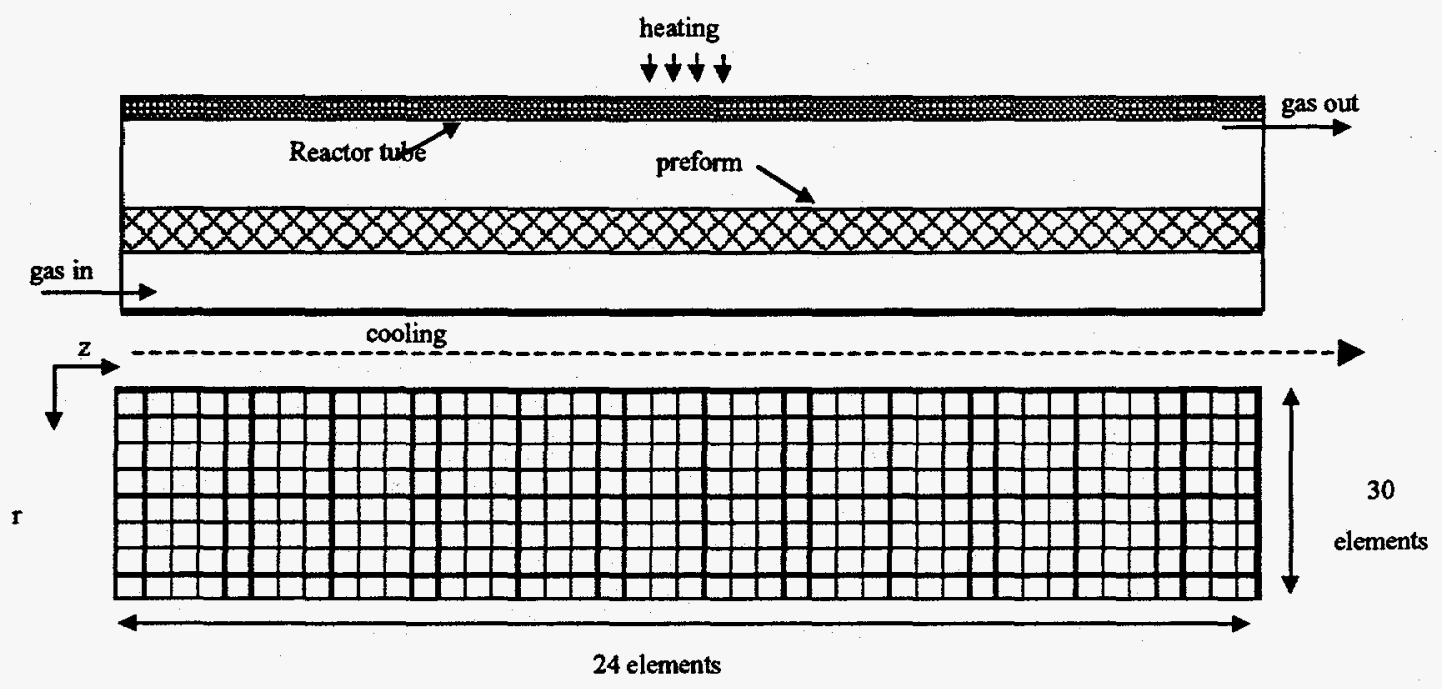

Figure 1. Cross-section view of tube CVI system shows schematic (upper) of furnace and preform arrangement with gas inlet and exhaust, and finite volume model (lower) in cylindrical coordinates.

\section{Tube Densification Using FCVI}

The CVI model is used to simulate the densification process for tubes using the FCVI process. In one configuration the preform is heated from the outside in a tube furnace with a cooling line through the center. Reactant gas is admitted into the center of the tube at one end and exhausted from outside the tube at the other end, establishing reactant flow in the direction of an increasing temperature gradient - the essential feature of the FCVI process. This arrangement is shown in Figure 1 for a tube of length $30.5 \mathrm{~cm}$ (12 inch), outer diameter $7.0 \mathrm{~cm}$ (2-3/4 inch) and thickness $1.27 \mathrm{~cm}(1 / 2 \mathrm{inch})$. The central cooling line has an outer diameter of $1.27 \mathrm{~cm}(1 / 2 \mathrm{inch})$ and the reactor tube has a thickness of $0.32 \mathrm{~cm}(1 / 8 \mathrm{inch})$ and outer diameter of $13.0 \mathrm{~cm}(5-1 / 2 \mathrm{inch})$. The gas inlet is just outside of the cooling line at one end of the tube and the exhaust is just inside the reactor tube at the other end. This configuration approximates that currently used at 


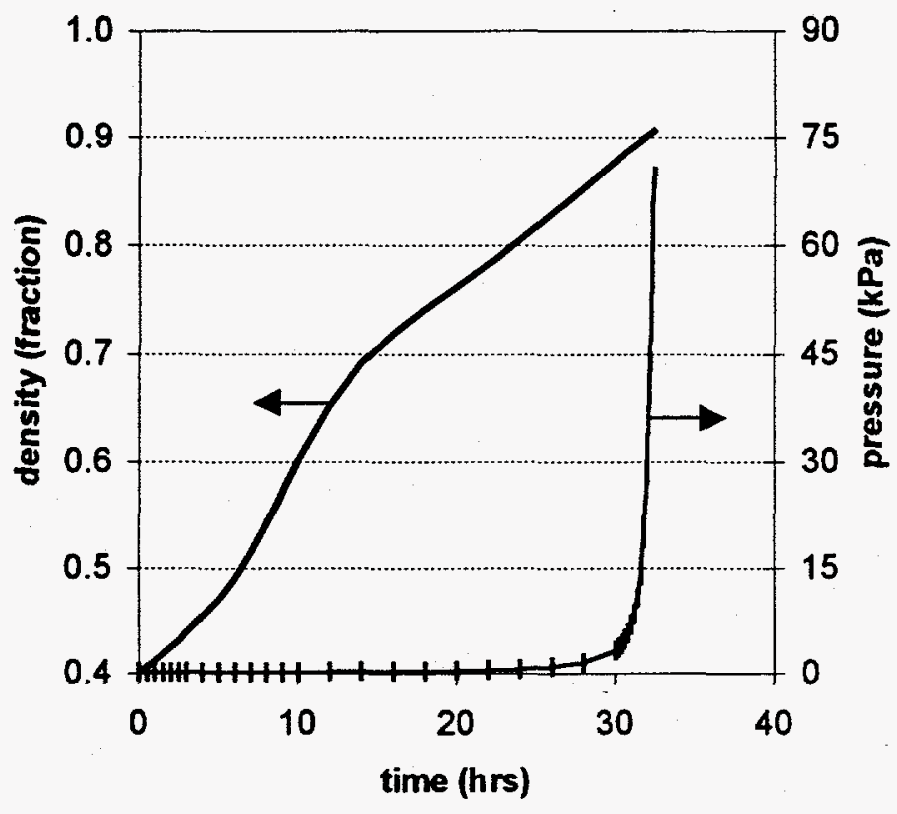

Figure 2. Density and pressure increase over time with full densification after 32 hours.

ORNL for tube densification. The preform for this model is square weave Nicalon fiber cloth as a $0 / 90$ layup and $40 \%$ fiber.

Model results are presented for the conditions: outside reactor tube temperature $1200^{\circ} \mathrm{C}$, cooling line temperature $50^{\circ} \mathrm{C}$ and $4.5 \mathrm{~L} / \mathrm{min}$ flow of reactant gas with composition 5:1 $\mathrm{H}_{2}:$ MTS. Figure 2 shows the overall densification behavior of the tube with these conditions. The process is complete (reaches a backpressure greater than 160 $\mathrm{kPa}$ ) after 32.4 hours. At this time the average density for the tube is $91 \%$ full density. Although the overall density increases at an approximately steady rate over the process period, the backpressure does not increase significantly until the last few hours. This behavior is typical for the FCVI process.

As expected the overall process time depends on the reactor temperature and reagent flow rate. The time decreases with increasing temperature and flow as shown in Figure 3. Densification time can be reduced to approximately ten hours by $a 0^{\circ} \mathrm{C}$ increase in temperature and a fourfold increase in flow rate. Again, these results are typical for the FCVI process and selection of "optimum" process conditions will be based 


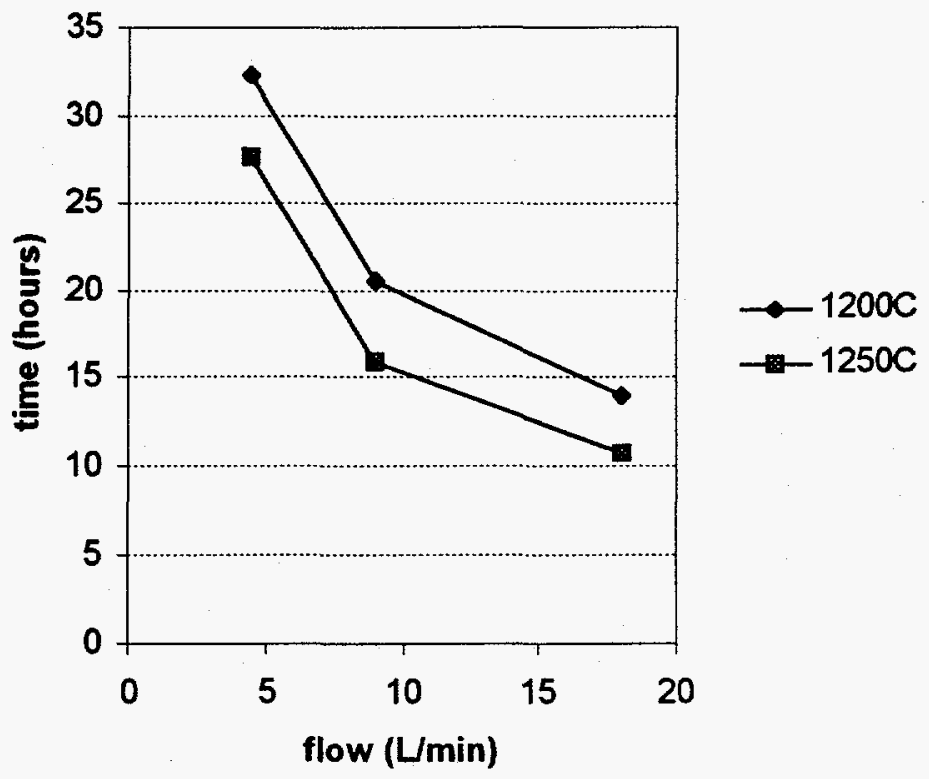

Figure 3. Densification time decreases with increasing flow rate and temperature.

on factors in addition to process time ${ }^{4}$. Such factors may include efficiency of reagent utilization, safety limit for hydrogen flow rate or temperature limitation of preform. All of the model runs yielded an average density greater than $90 \%$ full density.

In addition to evaluating the effect of various process parameters the model shows the evolving pattern of densification during the infiltration period. This pattern has a significant effect on the structure and properties of the final tube. This progressive densification is shown in Figure 4. Initially (Figure 4a) the densification rate is highest at the outer part of the tube near the inlet end and lowest at the inner part of the tube near the outlet. This pattern results from three factors. First, the low thermal conductivity of the preform creates a relatively steep temperature gradient which results in a lower reaction rate near the inside of the tube. Second, the flow pattern for this geometry is such that the radial velocity through the preform near the inlet end of the tube is higher than that near the outlet, yielding less depletion and lower overall reaction rate near the 


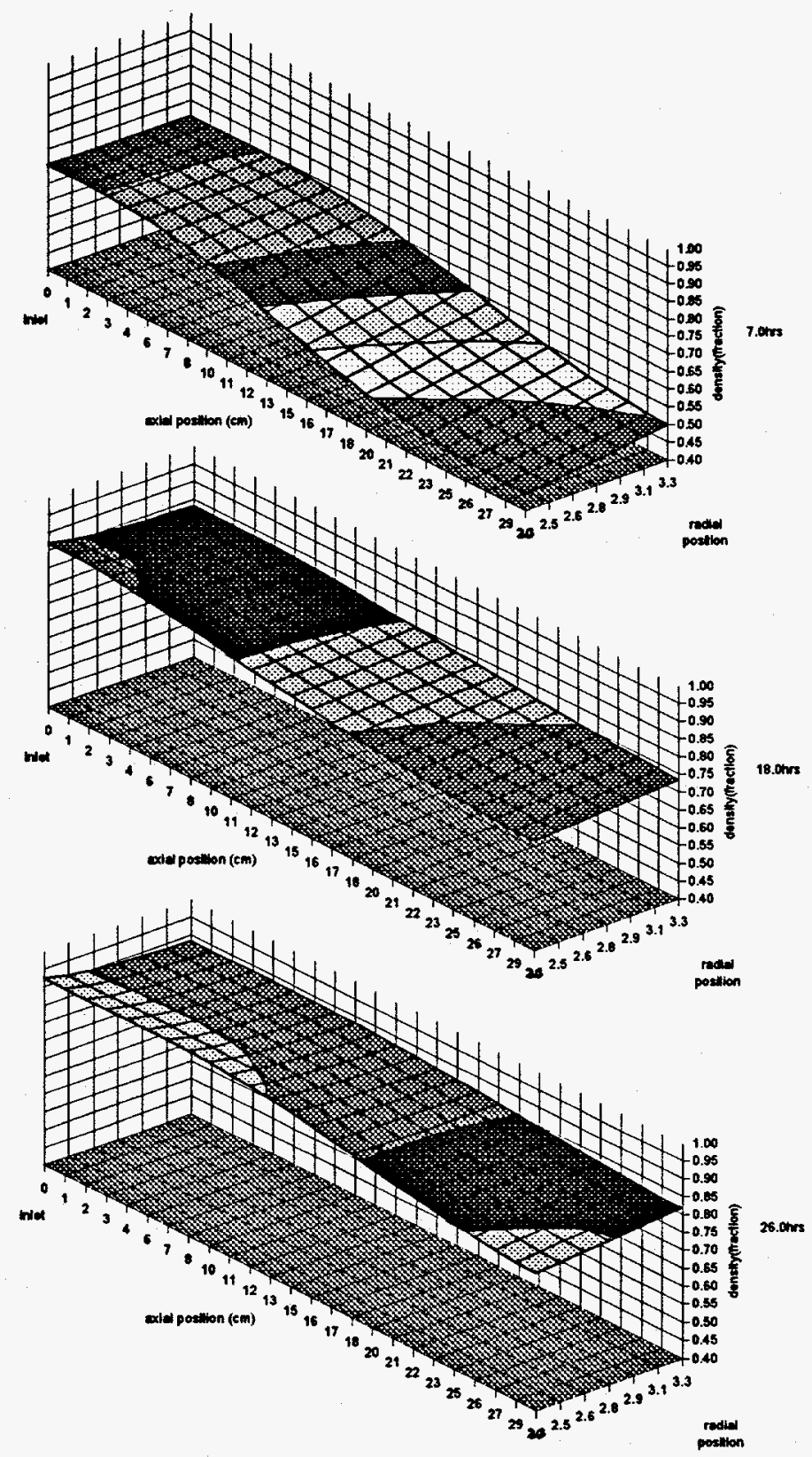

Figure 4. Model shows pattern of densification for tube CVI. Density increases progressively from inlet end. Near the end of the process the inner region of the tube reaches full density. 
inlet end. Third, cross-flow diffusion results in depletion of the reactant as it flows through the inside of the tube and this results in lower reaction rate near the outlet end. These factors produce a significant density variation along the length of the tube during the early stage of infiltration.

After several hours (Figure $4 \mathrm{~b}$ ) the inlet end of the tube is almost completely densified and the densification pattern through the tube thickness is different than in the early stages, i.e. the inner region of the tube is densifying at a higher rate than the outer region. This is the result of two factors. First, as the thermal conductivity of the composite increases the temperature gradient through the tube wall becomes less steep. Second, as the gas permeability decreases the radial gas velocity through the tube wall is reduced. Both changes favor higher deposition rate near the inside of the tube. Also the overall flow pattern is changed; the radial flow rate near the outlet end of the tube is much larger than that near the inlet.

These trends continue until the end of the process period where most of the tube length has reached nearly full density (Figure 4c). Only the end of the tube near the outlet has significant permeability and all of the gas flow is through this end. The backpressure rises quickly as this region approaches full density.

While the details of the process and the overall densification rate may change with changes in process parameters, this pattern of progressive densification does not. It is characteristic of the tube geometry and the reactant and exhaust gas configuration. Indeed, this densification pattern may be highly desirable for production of gas-tight tubes. Although the tube overall remains permeable at the "end" of the FCVI process, this permeability is localized at the outlet end of the tube. Most of the tube length is essentially gas-tight.

The relationship between density and gas permeability bears further discussion, although a fuller analysis is presented in another report ${ }^{5}$. Three properties of a porous material decrease as the density approaches its percolation limit - gas permeability, mass diffusivity and available surface area. Since the CVI deposition rate depends on all of these, densification also slows as the density approaches this limit. In the model, as described above, the percolation limit is uniform and precisely specified. For a real process with a real preform the percolation 


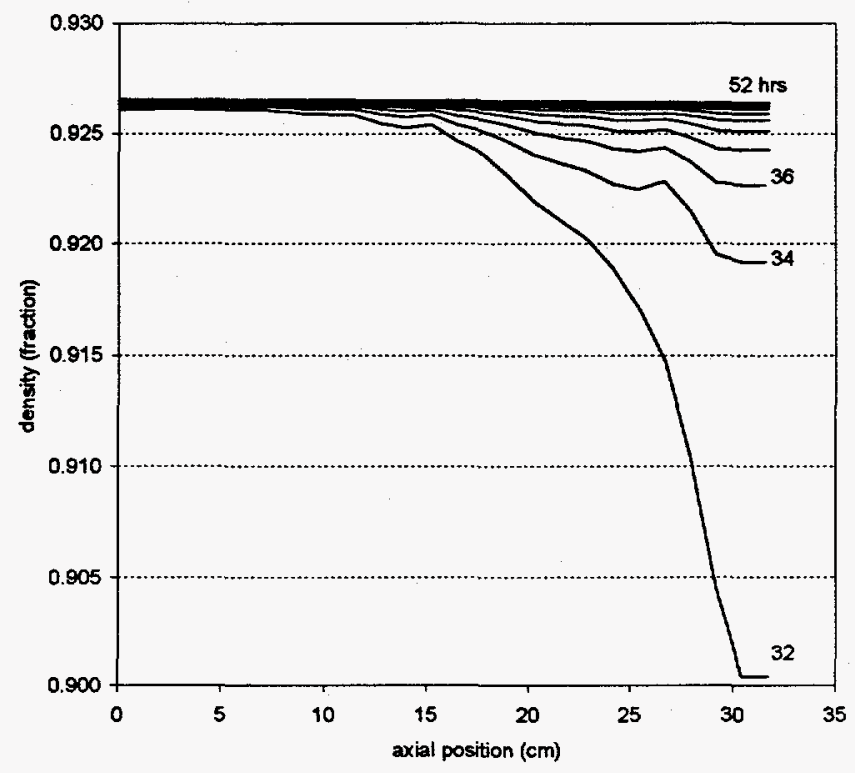

Figure 5. Density of tube near outlet end approaches full density after several hours of infiltration with gas outlet switched. Density plots are for two hour intervals.

limit is not that easily determined and likely will vary along the tube length. However, the model shows that with this infiltration configuration the tube wall will approach the local percolation limit along most of its length even though the absolute density may vary.

\section{Hybrid Process For Gas-Tight Tubes}

A new variation of CVI, proposed here, offers the potential for fabricating tubes that are fully gas-tight along their length. This "hybrid" process is identical to the FCVI process discussed above except that as the tube approaches full density the gas outlet point is switched from the outside of the tube to the inside. At this point the process is characterized as "isobaric"; there is no pressure difference across or flow through the preform thickness. Reactant transport into the porous composite is driven only by diffusion. The thermal gradient is maintained as before and densification continues until the inner region of the tube is completely dense. Figure 5 shows the continued densification that results when this switch is made after 32 hours of standard FCVI at the conditions of Figures 2 and 4 . The density of the inner region of the tube at the outlet end approaches that of the rest of the tube over several 
more hours of processing. Overall the density approaches the percolation limit and is essentially gas-tight over its entire length at the end of this hybrid CVI process.

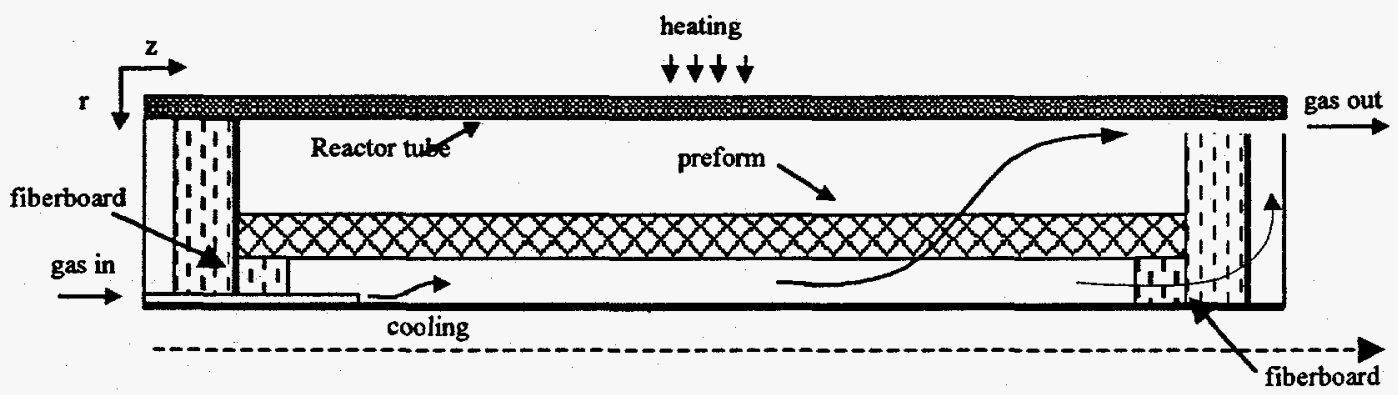

Figure 6. ORNL infiltration system utilizes porous fiberboard to hold and seal tube preform. Reactant gas can flow through preform or through fiberboard endcaps.

\section{ORNL PROCESS SIMULATION}

The Windows-based GTCVI model was delivered to ORNL and is being used to perform detailed simulations of their CVI reactor. Some of these results have been reported recently ${ }^{6}$. The ORNL reactor has been used to infiltrate tube preforms of various diameters and fiber compositions, and is similar to the idealized reactor shown schematically in Figure 1. One aspect of the ORNL reactor that is different relates to the method of mounting and sealing the tube preform in the reactor. This is accomplished using rings of a rigid ceramic fiberboard which establish the proper spacing and provide thermal insulation between the tube and the cooling line. This fiberboard is not impermeable and some fraction of the reactant gas will pass through it rather than through the tube as illustrated in Figure 6. The fraction of flow through the tube end depends on the relative permeabilities and dimensions of the two materials, and since the permeability of the tube decreases as it becomes denser, the partition of the flow will change during processing. 


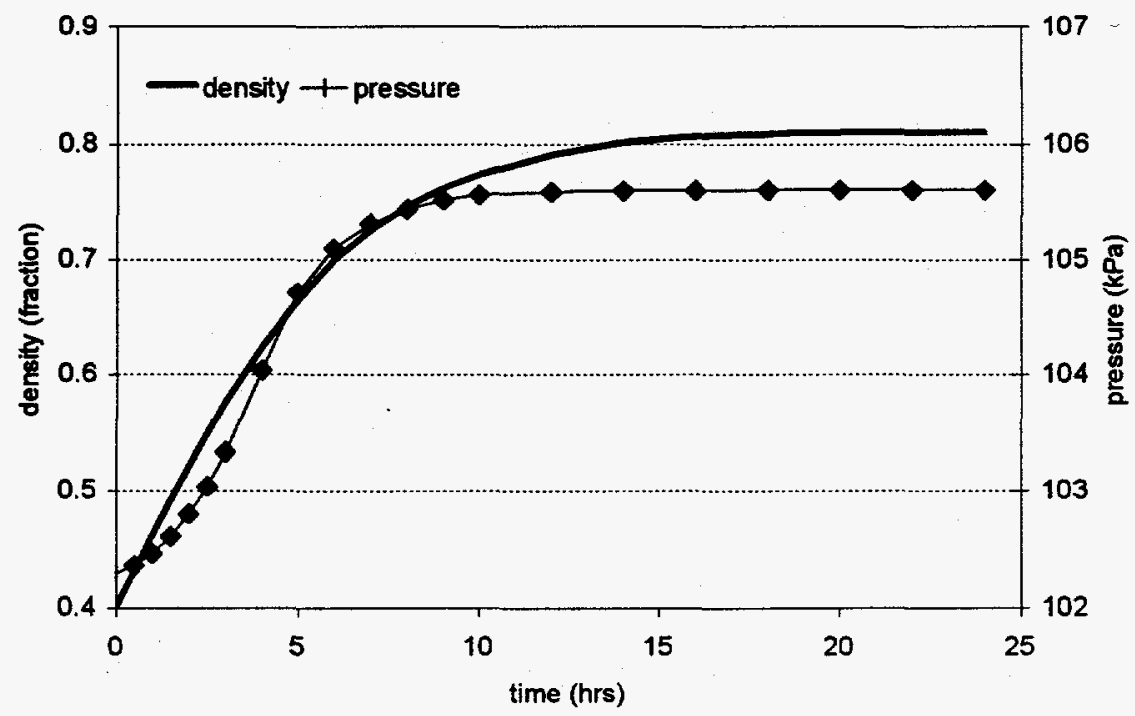

Figure 7. In the ORNL process density and pressure increase with time. While pressure plateaus at approximately $106 \mathrm{kPa}$, density continues to increase beyond this point.

Figure 7 shows the overall densification and backpressure behavior for a model run similar to an ORNL experimental run with fiberboard endcaps. The tube preform has an ID of $5.08 \mathrm{~cm}\left(2.0^{\prime \prime}\right)$ and a wall thickness of $0.635 \mathrm{~cm}(1 / 4)$. Also, the preform in this case is fabricated of Nextel braided sleeve which has a percolation limit significantly lower (more residual porosity) than the Nicalon square weave cloth layup ${ }^{7}$. Process conditions are similar to those used for the run corresponding to Figure $2\left(1200^{\circ} \mathrm{C}\right.$ and 5:1 $\left.\mathrm{H}_{2}: \mathrm{MTS}\right)$ but with a slightly higher reactant flow rate of $6 \mathrm{~L} / \mathrm{min}$. With a thinner preform, higher reactant flow rate and smaller diameter Nextel fiber the overall densification time is shorter than that for Figure 2. However, the pattern of densification is the same; the density increases more rapidly near the inlet end of the tube and progresses down the length of the tube as the permeability and flow pattern change. After a few hours of infiltration the backpressure begins to increase but, in contrast to Figure 2, remains essentially constant beyond ten hours even though the tube continues to densify. Figure 8 shows the distribution of gas flow out of the tube interior as a function of process time. Initially the flow passes through the preform. As the tube densifies 


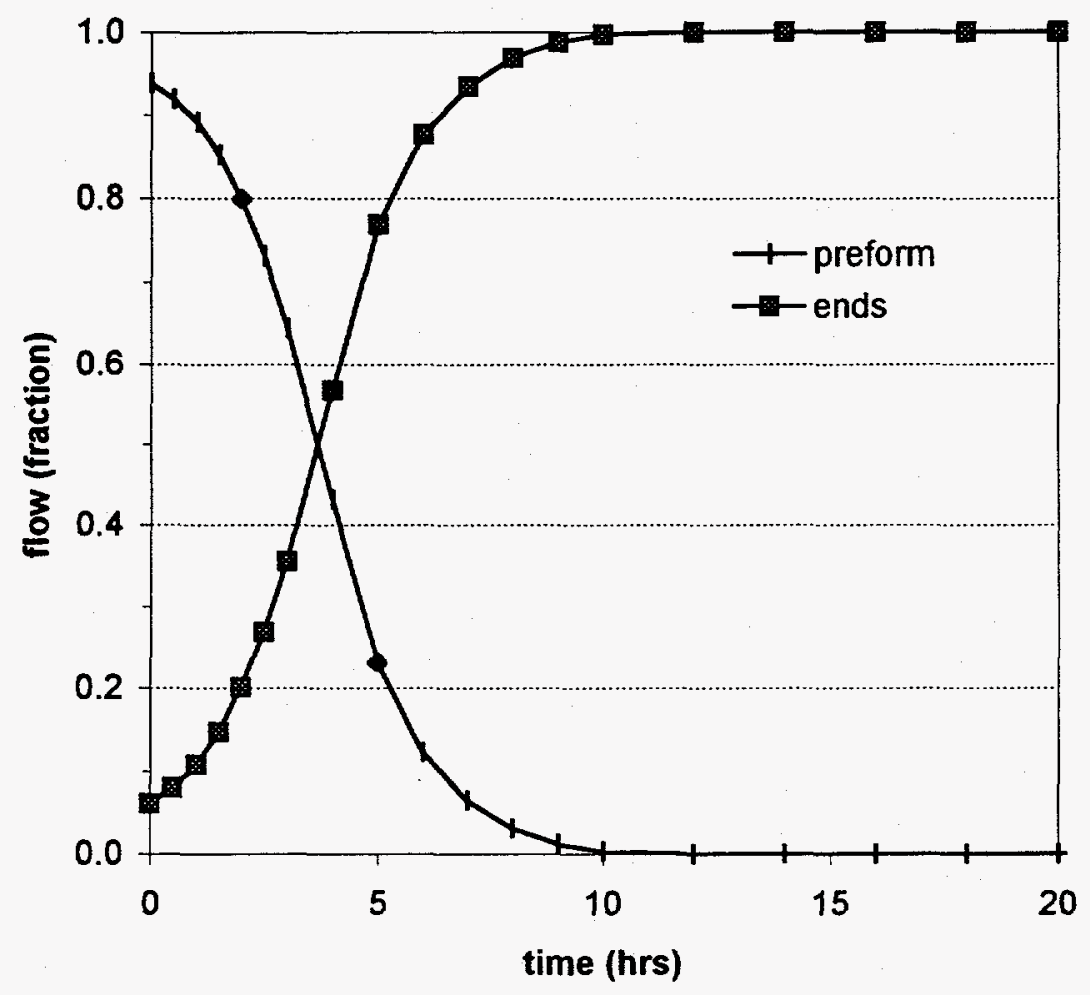

Figure 8. As tube becomes denser, more of gas flows through fiberboard endcaps producing continued densification in inside region of tube.

the flow switches to primarily through the fiberboard endcaps. This transition is essentially the same as the hybrid process discussed above and is capable of producing gas-tight tubes.

\section{SUMMARY}

Modifications of the our CVI model include linearization of radiation heat transfer and creation of a Windows-based operation. For tube preforms the model shows a pattern of progressive densification that results in gas-tight material over much of the tube length. A hybrid process involving switching of the gas outlet position near the end of the run and produces tubes that are gas-tight along their full length. GTCVI model has been transferred to ORNL and used for detailed simulation of their infiltration system. The use of permeable, 
fiberboard fixturing has the unexpected result of creating a flow transition similar to the hybrid process and shows potential for producing gas tight tubes.

\section{REFERENCES}

${ }^{1}$ T.L. Starr, "Modeling of Chemical Vapor Infiltration for Composite Fabrication," in High Temperature Ceramic Matrix Composites, R. Naslain, ed., European Association for Composite Materials, Bordeaux, France (1993)

${ }^{2}$ T.L. Starr and A.W. Smith, "Finite-Volume Model for Chemical Vapor Infiltration Incorporating Radiant Heat Transfer", Oak Ridge National Laboratory report ORNL/sub/8555901/05 (May 1995)

${ }^{3}$ Suhas V. Patankar, Numerical Heat Transfer and Fluid Flow, Hemisphere Publishing Corp. (New York, NY, 1980)

${ }^{4}$ D.Y. Chiang and T.L. Starr, "Optimization of Composite Processing Using CVI," pp.381-389 in Proceedings of the American Society for Composites: Eleventh Technical Conference, Atlanta, GA, October 7-9, 1996, W.S. Johnson, ed., Technomic Publishing, Lancaster, PA, 1996.

${ }^{5}$ T.L. Starr, O.G. Fiadzo and N. Hablutzel, "Structure and Properties of Braided Sleeve Preforms for Chemical Vapor Infiltration", Oak Ridge National Laboratory report ORNL/sub/87-00184/07, April 1998.

${ }^{6}$ K.J. Probst, T.J. Anderson, T.M. Bessman, J.C. McLaughlin and T.L. Starr, "ModelAided FCVI for Tubular Geometries," International Symposium on Advanced Synthesis and Processing, Cocoa Beach, FL, January 21-23, 1998

${ }^{7}$ T.L. Starr, D.Y. Chiang, O.G. Fiadzo and N. Hablutzel, "Mass Transport Measurements And Modeling For Chemical Vapor Infiltration", in Proceedings of the Eleventh Annual Conference on Fossil Energy Materials, May 20-22, 1997, D.P. Stinton and R. R. Judkins, eds., Oak Ridge National Laboratory, Oak Ridge, TN, 1997 
3M COMPANY

Ceramic Materials Department

201-4N-01 3M Center,

St. Paul, MN 55144

M. A. Leitheiser

AIR PRODUCTS AND CHEMICALS

P.O. Box 538

Allentown, PA 18105

S. W. Dean

\section{ALLISON GAS TURBINE DIVISION}

P.O. Box 420

Indianapolis, IN 46206-0420

P. Khandelwal (Speed Code W-5)

R. A. Wenglarz (Speed Code W-16)

AMA RESEARCH \& DEVELOPMENT CENTER 5950 McIntyre Street

Golden, CO 80403

T. B. Cox

\section{ARGONNE NATIONAL LABORATORY}

9700 S. Cass Avenue

Argonne, IL 60439

W. A. Ellingson

J. P. Singh

BABCOCK \& WILCOX

Domestic Fossil Operations

20 South Van Buren Avenue

Barberton, $\mathrm{OH} 44023$

M. Gold

BRITISH COAL CORPORATION

Coal Technology Development Division

Stoke Orchand, Cheltenham

Glocestershire, England GL52 4ZG

J. Oakey

CANADA CENTER FOR MINERAL \& ENERGY

TECHNOLOGY

568 Booth Street

Ottawa, Ontario

Canada KIA OG1

R. Winston Revic

Mahi Sahoo
DOE

DOE OAK RIDGE OPERATIONS

P.O.Box 2001

Oak Ridge, TN 37831

Assistant Manager for

Energy Research and Development

DOE

DOE OAK RIDGE OPERATIONS

P. O. Box 2008

Building 4500N, MS 6269

Oak Ridge, TN 37831

M. H. Rawlins

DOE

OFFICE OF BASIC ENERGY SCIENCES

Materials Sciences Division

ER-131

19901 Germantown Road

Germantown, MD 20874-1290

H. M. Kerch

DOE

IDAHO OPERATIONS OFFICE

P. O. Box 1625

Idaho Falls, ID 83415

J. B. Malmo

DOE

FEDERAL ENERGY TECHNOLOGY CENTER

3610 Collins Ferry Road

P.O. Box 880

Morgantown, WV 26507-0880

R. C. Bedick

D. C. Cicero

F. W. Crouse, Jr.

R. A. Dennis

N. T. Holcombe

W. J. Huber

T. J. McMahon

J. E. Notestein 


\author{
DOE \\ FEDERAL ENERGY TECHNOLOGY CENTER \\ 626 Cochrans Mill Road \\ P.O. Box 10940 \\ Pittsburgh, PA 15236-0940 \\ A. L. Baldwin \\ G. V. McGurl \\ L. A. Ruth \\ T. M. Torkos \\ DOE \\ OFFICE OF FOSSIL ENERGY \\ FE-72 \\ 19901 Germantown Road \\ Germantown, MD 20874-1290 \\ F. M. Glaser \\ DOE \\ OFFICE OF VEHICLE AND ENERGY R\&D \\ CE-151 Forrestal Building \\ Washington, DC 20585 \\ R. B. Schulz
}

DOW CORNING CORPORATION

3901 S. Saginaw Road

Midland, MI 48686-0995

H. Atwell

EC TECHNOLOGIES

3614 Highpoint Drive

San Antonio, TX 78217

D. J. Kenton

ELECTRIC POWER RESEARCH INSTITUTE

P.O. Box 10412

3412 Hillview Avenue

Palo Alto, CA 94303

W. T. Bakker

J. Stringer

EUROPEAN COMMUNITIES JOINT RESEARCH

CENTRE

Petten Establishment

P.O. Box 2

1755 ZG Petten

The Netherlands

$M$. Van de Voorde
GEORGIA INSTITUTE OF TECHNOLOGY

Materials Science \& Engineering (0245)

Bunger-Henry Building, Room 276

Atlanta, GA 30332-0245

T. L. Starr

IDAHO NATIONAL ENGINEERING \& ENVIRONMENTAL LABORATORY

P. O. Box 1625

Idaho Falls, ID 83415

B. H. Rabin

LAWRENCE LIVERMORE NATIONAL LABORATORY

P.O. BoX 808, L-325

Livermore, CA 94550

W. A. Steele

NATIONAL MATERIALS ADVISORY BOARD

National Research Council

2101 Constitution Avenue

Washington, DC 20418

K. M. Zwilsky

OAK RIDGE NATIONAL LABORATORY

P.O. Box 2008

Oak Ridge, TN 37831

T. M. Besmann

P. T. Carlson

J. M. Crigger (4 copies)

R. R. Judkins

R. A. Lowden

D. P. Stinton

M. R. Upton

OFFICE OF NAVAL RESEARCH

Code 431, $800 \mathrm{~N}$. Quincy Street

Arlington, VA 22217

S. G. Fishman

SHELL DEVELOPMENT COMPANY

WTC R-1371

P.O. Box 1380

Houston, TX 77251-1380

W. C. Fort 
TENNESSEE VALLEY AUTHORITY

Energy Demonstration \& Technology

MR2N58A

Chattanooga, TN 37402-2801

C. M. Huang

THE JOHNS HOPKINS UNIVERSITY

Materials Science \& Engineering

Maryland Hall

Baltimore, MD 21218

R. E. Green, Jr.

THE MATERIALS PROPERTIES COUNCL, INC. United Engineering Center

345 E. Forty-Seventh Street

New York, NY 10017

M. Prager

THE NORTON COMPANY

High Performance Ceramics Division

Goddard Road

Northborough, MA 01532-1545

N. Corbin

THE TORRINGTON COMPANY

Advanced Technology Center

59 Field St.

Torrington, CT 06790

W. J. Chmura

UNION CARBIDE CORPORATION

Linde Division

P.O. Box 44

175 East Park Drive

Tonawanda, NY 14151-0044

Harry Cheung

UNITED TECHNOLOGIES RESEARCH CENTER

MS 24, Silver Lane

East Hartford, CT 06108

K. M. Prewo

UNIVERSITY OF TENNESSEE

Dept of Materials Science and Engineering

Knoxville, TN 37996-2200

P. K. Liaw
UNIVERSITY OF WASHINGTON

Department of Materials Science and

Engineering

101 Wilson, FB-10

Seattle, WA 98195

T. G. Stoebe

VIRGINIA POLYTECHNIC INSTITUTE STATE UNIVERSITY

Department of Materials Engineering

Blackburg, VA 24601

W. A. Curtin

K. L. Reifsnider

WESTERN RESEARCH INSTITUTE

365 N. 9th Street

P.O. Box 3395

University Station

Laramie, WY 82071

V. K. Sethi

WESTINGHOUSE ELECTRIC CORPOR NTION

Research and Development Center

1310 Beulah Road

Pittsburgh, PA 15235-5098

S. C. Singhal 